Gerión. Revista de Historia Antigua

ISSN: 0213-0181

http://dx.doi.org/10.5209/geri.68593

\title{
Sobre la identificación de dioses íberos en las inscripciones
}

\author{
Jesús Rodríguez $\operatorname{Ramos}^{1}$
}

Recibido: 5 de noviembre de 2019 / Aceptado: 23 de febrero de 2020

Resumen. Reavivado el debate de la identificación de nombres de dioses íberos por la aparición de nuevas inscripciones latinas y los estudios de Joan Ferrer sobre inscripciones rupestres, es el momento adecuado para revisar tanto las nuevas propuestas como las antiguas, así como para plantear nuevas posibilidades. Se presta especial atención a la posibilidad de identificar la presencia de dioses extranjeros (como sucede en epigrafías similares, tales como la griega o la etrusca). Dada su rareza fonotáctica, es probable que las formas íberas -al y balkar sean préstamos, por lo que la interpretación de balkar como una adaptación del teónimo Melqart resulta especialmente interesante.

Palabras clave: epigrafía ibérica; inscripciones íberas votivas; dioses íberos; neitin iunstir; Neton; Melqart.

\section{[en] On the Identification of Iberian Gods in the Inscriptions}

Abstract. Revived the debate on the identification of gods' names thanks to the discovery of new Latin inscriptions and to the studies on rock inscriptions by Joan Ferrer, the time has come to review critically these new proposals along with the older ones, and to search for new possibilities. Special attention is paid to the possibility of identification of foreign gods (as it happens in similar epigraphies, such as Greek or Etruscan). Due to their phonotactical rarity Iberian -al and balkar are likely to be lexical borrowings; hence the interpretation of balkar as an adaptation of the god's name Melqart is especially appealing.

Keywords: Iberian Epigraphy; Votive Iberian Inscriptions; Ancient Iberian Gods; neitin iunstir; Neton; Melqart.

Sumario: 1. Introducción. 2. La identificación gramatical de "dedicados" en inscripciones. 3. Los teónimos nativos en inscripciones latinas. 4. Algunos posibles teónimos de las inscripciones íberas. 4.1. neitin y iunstir. 4.2. La presunta relación entre neitin y el dios Neton. 5. Las fórmulas votivas en Liria. 6. El monograma de ka(uŕ)ko-(ŕ). 7. Las inscripciones rupestres. 8. Los posibles teónimos y sus paralelos alóctonos. 9. Conclusiones. 10. Referencias bibliográficas.

Cómo citar: Rodríguez Ramos, J. (2020): Sobre la identificación de dioses íberos en las inscripciones, en Gerión 38/1, 259-284.

1 Dr. en Historia Antigua por la Universidad de Barcelona.

E-mail: jrr_ib@hotmail.com 
Al prof. José Fortes Fortes (1938-2012) amigo y maestro, en cuyo Homenaje no tuve ocasión de participar

\section{Introducción}

La cuestión de la identificación de teónimos íberos ha venido siendo tratada con desigual fortuna y de forma episódica, de modo que, si bien algunos resultados han sido interesantes, han sido limitados. Esto viene cambiando desde hace unos pocos años, tanto por la identificación de algunos teónimos en inscripciones latinas como por la mejora del conocimiento de las marcas de dativo en la lengua íbera y los estudios de Ferrer sobre las inscripciones rupestres. Es por ello que parece que es el momento adecuado para hacer una revisión crítica del tema, tanto de contenido como de planteamientos.

Aclaremos, con todo, antes de entrar en materia, una cuestión sobre las transcripciones. No es el objetivo del presente artículo debatir los problemas de algunas transcripciones que se publican, salvo en los casos que sean relevantes. Esto atañe especialmente a la dualización forzada de algunas inscripciones, a veces a partir de la más mínima sospecha. La transcripción de un texto debe ser un reflejo fiel de la información real. Cuando ésta presenta algún problema debe evitarse una inclusión de datos supuestos o marcarse de forma que no confunda al lector, diferenciando bien una eventual interpretación del texto de la transcripción.

Las transcripciones duales son relativamente seguras en las inscripciones de la zonas B y C (básicamente Cataluña y sur de Francia), como demostrara Correa, ${ }^{2}$ antes de hacia el 200 a.C. ${ }^{3}$ Asimismo debe observarse que la paleografía indica

Correa 1992. Este sistema de distinción ya aparece explicado como válido tanto en la síntesis de Correa 1994, 268, como en el manual divulgativo de Rodríguez Ramos 1995a, 43-44. La idea de que pudiera haber una distinción entre los silabogramas en escritura íbera fue planteada por Maluquer de Motes 1968, 53-54, a partir de la observación de dos plomos (C.2.3 y F.6.1), sugiriendo que debía de ser para diferenciar entre sordas y sonoras. Aunque las lecturas de los signos las presenta como arbitrarias, indicando que les da una "atribución hipotética a sorda o sonora, puesto que el aspecto lingüístico del problema no queremos abordarlo aquí", se tiene la impresión de que efectivamente hay más estudio previo tras esa propuesta que una mera arbitrariedad, sólo que, como solía, prefirió dejar ciertas cuestiones a filólogos. Efectivamente este planteamiento fue ampliado y apoyado poco después por Mariner 1972, dando una primera base fonética al compararlo con términos con -ld- en inscripciones greco-ibéricas; mientras que De Hoz 1985, 453, amplía a una docena las correlaciones con segmentos grecoíberos y nombres galos concluyendo que es un fenómeno coherente y sistemático. Pero es el documentadísimo estudio de Correa 1992, el que muestra la correlación sistemática tanto con las transcripciones latinas de antropónimos íberos, como las íberas de antropónimos alóctonos galos y latinos. Finalmente en Rodríguez Ramos 2004, 243-255, se efectúa un estudio fonotáctico de los propios textos íberos que muestra no sólo que el sistema reproduce pautas fonotácticas consistentes, sino efectivamente coherentes con una distinción según el rasgo de sonoridad (apoyando el que no se trataría de una correlación gráfica entre distinciones fonológicas diferentes).

3 Rodríguez Ramos 1997, 24. De nuevo es en Correa 1992, 290-291, donde se propone una primera cronología a partir de la datación de una decena de inscripciones selectas para indicar que se documentan ejemplos de su uso en los siglos IV, III y II a.C. Paralelamente Quintanilla 1993, 241, indica que por la datación de las inscripciones "cabe suponer que la representación de sonoridad fue un uso practicado en época temprana", sugiriendo que pudo desaparecer por la influencia griega, pero ni delimita el marco cronológico ni aporta ningún ejemplo de inscripción datada y, si tenemos en cuenta que la influencia griega en la zona data al menos del s. VI a.C., su afirmación es muy imprecisa. El estudio de Rodríguez Ramos, basado en 1400 inscripciones y explicado in 
que entre las zonas con signarios arcaizantes en el s. II a.C. se encuentra el Pirineo Central, incluyendo las inscripciones rupestres de la Cerdaña, ${ }^{4}$ dado que algunas muestran signos propios de ese signario especial. En estos casos, por defecto puede seguirse la transcripción dual normal, pero podría haber sorpresas.

Sin embargo, para la zona F (básicamente Edetania), pese a continuas aseveraciones optimistas por parte de Ferrer y el resto del grupo Littera de la Universidad de Barcelona, ${ }^{5}$ las cosas distan de estar solucionadas: no se ha publicado ningún estudio que avale tan enfáticas afirmaciones, pero sí discrepancias y contraejemplos. ${ }^{6}$ En todo caso, aquí adoptaremos, para los casos en que consideremos conveniente una transcripción de tipo dual, la convención indicada en Rodríguez Ramos: ${ }^{7}$ un superíndice d cuando se considere dual el segmento y cuando se indique cómo quedaría un segmento edetano transcrito en forma dual un superídice ${ }^{\mathrm{e}=\mathrm{d}}$ (sistema edetano transcrito como dual).

\section{La identificación gramatical de "dedicados" en inscripciones}

Dado que una ubicación típica de teónimos es en inscripciones votivas que indican que se les da/consagra algo, para su identificación será clave la localización de marcas de una función sintáctica de beneficiario.

Como marca de dativo se suele aceptar la teoría de Untermann de que correspondería a un sufijo -e. ${ }^{8}$ Posteriormente Orduña ${ }^{9}$ identificó el alomorfo -er, mientras que Rodríguez $\operatorname{Ramos}^{10}$ realiza una revisión de la problemática, ampliando

extenso en Rodríguez Ramos 2004, 101-234, con detalles de unos 400 casos selectos, corrige los ejemplos usados por Correa para el s. II a.C.; y no sólo se detalla el momento final del sistema dual, sino que también se hacen observaciones sobre la cronología de uso tanto sobre sistemas similares locales (las formas edetanas parecen perdurar más) como de signos típicamente duales en inscripciones no duales.

Rodríguez Ramos 1997, 14.

5 No sólo se presentan como solucionadas, sino que las críticas no son ni mencionadas. La imagen que se transmite es tan unilateral que se refiere por sistema a Ferrer 2005, incluso la cronología del sistema dual y, amén de implícitamente, incluso explícitamente se le presenta como el descubridor del sistema dual: Velaza destaca entre los descubrimientos más importantes de los últimos años "the identification of the so-called dual script, an achievement owed to Joan Ferrer" (Velaza 2016, 483). En todo caso, el que durante años no se quisiera prestar atención a estudios muy documentados y contundentes (en especial Correa 1992), no es "mérito" que justifique semejante promoción de Ferrer 2005, donde a partir de una novedad epigráfica identifica la forma sorda de ta. Obsérvese que incluso antes de la novedad epigráfica al menos en una ocasión ya se había sugerido expresamente la posibilidad de que una variante de bo acabase siendo en realidad la forma marcada de ta dual indicando "Veremos lo que las inscripciones que aparezcan en el futuro tienen que decir al respecto" (Rodríguez Ramos 2001, 286, n. 11).

6 Rodríguez Ramos 2008, 586; 2014, 92, y 2018, 192, n. 8, y De Hoz 2011, 187-188. Sobre Correa 1992, De Hoz dice "cabe aceptar las conclusiones de ese estudio y asumir que la distinción fue utilizada casi sistemáticamente en el sur de Francia y muy ampliamente en Cataluña (...) la influencia de la innovación alcanzó también al parecer a algunos escribas del territorio edetano, pero sin extenderse ampliamente". De Hoz critica también el uso de negritas cursivas para transcribir y advierte contra la asunción prematura de un texto como dual, prefiriendo una transcripción más neutra del tipo tí / ti ("una de las ventajas de la simple utilización del acento (...) es que no implica necesariamente que el texto sea dual"). Este sistema de tildes es el usado en el banco de datos Hesperia (http://hesperia.ucm.es/).

Rodríguez Ramos 2018, 192.

Untermann 1984, 113, y 1985, 43.

Orduña 2005, 64 y 313-314.

Rodríguez Ramos 2017. 
la fundamentación e identificando un alomorfo -ir. En dicho trabajo se insiste en la idea de que, aunque -e / -er / -ir serían propiamente dativos-benefactivos, el considerado genitivo posesivo -ar / -en acepta usos afines al dativo (como una especie de dativo-genitivo). Esto es relevante en tanto que tras alguna presunta "marca de propiedad" en -ar / -en podríamos tener un teónimo como dedicado de una ofrenda.

Por el contrario, las formas -ka, para las que en alguna ocasión se ha manejado la posibilidad de un sentido dativo, no parecen admitir dicha función, pues parecen marcar al deudor de un préstamo y, en todo caso, parecen tener una función muy especializada. ${ }^{11}$

En lo que respecta al dedicante de una inscripción votiva (información harto útil para, por contraste, buscar un teónimo), las cosas no son claras. El caso más evidente que podríamos esperar es el del sufijo agente -te de las marcas de acción (tipo N.P.te ekiar equivalente a Caius fecit), pero no es tan frecuente como debiera y cabe sospechar la presencia de sujetos agente sin marca. ${ }^{12}$

En todo caso, dados algunos problemas imaginarios que se aprecian en trabajos sobre teónimos, resulta menester recordar que la función de dativo no es gramaticalmente exclusiva de dioses, pudiendo atribuirse también como mínimo a personas, amén de otros posibles usos sintácticos que acepte el caso. Específicamente como posibles usos de dativo marcando divinidades en Rodríguez Ramos ${ }^{13}$ se indican, aparte de los términos en betan de los que trataremos infra: el inicio de la roca C.10.1 ba]śtaneś-e (con dudas) y los artiunan-er (B.23.14) y baśban-ir (B.23.2) de Osséja; así como la posibilidad de tener otro dativo en atun-e (F.9.6/7).

\section{Los teónimos nativos en inscripciones latinas}

Recientemente se ha propuesto la identificación de tres que son probablemente íberos: BETATVN, SALAECO y SERTVNDO. Quizás el más claro es SALAECO ${ }^{14}$ que no sólo es explicable como śalai+ko, sino que la conexión de śalai con śalir

11 Rodríguez Ramos 2016, 245-254. El planteamiento de -ka / -ke como dativo tiene su interés en tanto que se ha utilizado para proponer la presencia de teónimos en las estelas C.10.1 (auŕunin-, oŕtinsei-) y de Guissona (neitin-, suba-) (Rodríguez Ramos 2002b, 127-128, y 2005b, 29-31). Aunque por motivos independientes, como neitin o la coincidencia con términos de inscripciones procedentes de tumbas, sigue habiendo buenas posibilidades de que sean estelas votivas con teónimos, dada la problemática del sufijo -ka, en este trabajo prescindiremos de su análisis. Cabe, sí, señalar, dado lo que luego trataremos, el parecido entre el término kananike (H.5.1), sobre cuenco de plata, con el término ‘cananeo’ con que los púnicos se referían a sí mismos (Rodríguez Ramos 2002b, 127, n 24). Todavía S. Agustín (Ep. Rm. Inch. 13) recoge que los púnico parlantes responden que son chanani.

12 El esquema de oposición -te / -e ha sido identificado por Díaz - Mínguez 2009 en la inscripción de La Cabañeta, donde el dedicante sería atintaneś-te y el dedicado teitataŕ-e. Enfoque similar en Moncunill et alii 2016, sobre la piedra de Cruzy donde el dedicado sería kuleśar-e. Ambos dedicados podrían ser dioses, aunque el contexto de La Cabañeta podría apuntar a un regalo. En todo caso, merece atención la idea de Orduña 2018, 425, de ver en ilun el dios destinatario de la inscripción (con sufijo -ate) y en kuleśar-e la persona en cuyo beneficio se hace el monumento ( $p r o$ ), dado que hay diversos motivos para esperar que ilun sea el teónimo, por más que, al menos en la actualidad, yo preferiría una explicación diferente para su idea sobre -ka / -kate / -ate / aquitano -ATE.

13 Rodríguez Ramos 2017. Sobre los indicios a favor de considerar C.10.1 como votiva y no funeraria a partir de su léxico específico véase Rodríguez Ramos 2005b, 29-31.

14 Velaza 2015. 
(cf. NIC 129) -un conocido término relacionado con monedas y valores- encaja semánticamente bien con que la inscripción se hallara en una mina. Igualmente perfecto sería SERTTVNDO, ${ }^{15}$ salvo el detalle de que seŕtun (NIC 118) no es precisamente un formante frecuente y que la nueva lectura de $\mathrm{R}$ se ha hecho precisamente por él.

El caso de BETATVN ${ }^{16}$ merece mayor comentario, pues, aunque se publicó como claramente íbero, dista de ser tan claro. Geográficamente apareció en una zona limítrofe entre lo bastetano, lo oretano y lo turdetano, por lo que su ibericidad es cuestionable. Formalmente, aunque se han planteado diversas comparaciones con el léxico íbero, todas presentan problemas ${ }^{17}$ y se ha prestado poca atención a si las crasis vocálicas propuestas se ajustan a los paralelos, ${ }^{18}$ sobre todo en formantes documentados con final en consonante. Incluso la propuesta de Ferrer, ${ }^{19}$ basada en la novedad epigráfica BETEPE[, no atiende al inicio en P del segundo formante de su ejemplo, que normalmente se explicaría por efecto de una consonante no escrita final y por tanto ha de ser un caso de beteś. ${ }^{20}$ Una alternativa para solucionar la crasis vocálica es suponer que no la hubo y que el formante final no es ATVN, sino to $\left(\mathrm{NIC}^{21} 157\right)$, pero es problemático en tanto que hay indicios de que era ${ }^{\mathbf{d}} \mathbf{d o}$ con sonora. Finalmente, nos queda una posibilidad con menos problemas técnicos, que no parece haberse tenido en cuenta. Dado lo típica que es la alternancia vocálica e/i en íbero, más la mayor oscilación en su "interpretatio latina" quizás pudiera interpretarse BETATVN como bitu (NIC 49; betu-kine en F.17.2) y atun, donde el 'sandhi' sería menos sorprendente. La conclusión es igualmente que la ibericidad de BETATVN no es obvia.

\section{Algunos posibles teónimos de las inscripciones íberas}

Es un tema especialmente difícil. En algunos casos hay problemas de lectura o incluso de autenticidad de la inscripción. Mucho depende del análisis interno del texto, raramente unívoco. En el terreno comparativo, aparte de lo comentado sobre las comparaciones con el aquitano, sería verosímil localizar menciones a dioses extranjeros de culturas influyentes, como se documenta tanto en la religión etrusca como en la propia griega. ${ }^{22}$ Una candidata obvia sería Artemis Efesia, cuyo culto y rito indica Estrabón ${ }^{23}$ que introdujeron los massaliotas desde sus enclaves en zona íbera. Se conocen numerosas imágenes íberas coincidentes especialmente con

\footnotetext{
Vidal 2016, 196-200.

Corzo et alii 2007.

NIC 18 y 42/2.

Los casos conocidos de 'sandhi' vocálico resultante en 'a' son el enlace e-a e i-a pero es más normal la conservación de ambas vocales (Correa 1994, 270; Quintanilla 1998, 131-134; Rodríguez Ramos 2005a, 3334).

19 Ferrer 2018a, 112.

20 Así se confirmaría el carácter onomástico beteś-kon (C.22.2; NIC 88a), mientras que los casos como TANNEPAISER- (CIL II 5840) se explicarían como ejemplos de taneś, confirmándose que taneś y TANNE son el mismo formante. El ensordecimiento no afecta a los casos de $\mathrm{G}$ inicial por ser un fonema distinto a $\mathrm{k}$, mientras que p es un alófono. Véase también Quintanilla 1998, 268-269, y Rodríguez Ramos 2004, 251.

21 Abreviamos así Rodríguez Ramos 2014.

22 Así Aplu (Apolo), Atunis (Adonis), Artumes / Aritimi (Artemis), Hercle (Heracles), entre otros.
}

23 Str. 4.1.5. 
la Artemis alada potnia theron..$^{24}$ Esto tiene relevancia incluso epigráfica pues en Grecia las mujeres le rinden culto consagrando elementos de la producción textil, no sólo vestidos finos, sino herramientas como pesas de telar y fusayolas, ${ }^{25}$ "viejos conocidos" de la epigrafía íbera. ${ }^{26}$

En consonancia con esta premisa pueden recordarse cuatro propuestas relativas a Proserpina (baseŕbina), Enualio (enuali), Tanit (tanito) y Neton (neitin). Todas son problemáticas. Las dos últimas, por su complejidad, las trataremos más adelante. Tanit por su relación tanto con el apartado de las rupestres como con la cuestión de las adaptaciones fonéticas púnicas; Neitin por su asociación especial con iunstir y lo problemático tanto de su supuesta relación con Neton como de la propia supuesta celticidad de este último.

Enuali (C.18.8) como corrección a la lectura enubili de una inscripción sobre mármol conservada sólo por dibujo que podría hacer referencia al dios de la guerra Enualio. ${ }^{27}$ Es posible, por más que es perfectamente correcta la clasificación que hace $\operatorname{Simón}^{28}$ de la inscripción como de autenticidad suspecta. En todo caso sí conviene matizar que la línea argumental de que fuese una falsificación intentando referirse a Endovélico ${ }^{29}$ ya fue discutida por Hübner, ${ }^{30}$ a partir de una lectura inicial 'entpli', quien señala que tras realizar autopsia de la misma la considera totalmente auténtica. Por otra parte, si consideramos que es un falso basado en Endovélico, una sencilla "reconstrucción del crimen" plantea preguntas legítimas. ¿Por qué para ello se habría usado el signo u con la presunta lectura $T$ en vez del signo tu que incluso los estudios obsoletos leían D o el ta que algunos leían D por la equivalencia iltiŕ-ta / ILER-DA? ¿Por qué no se añadió el signo ke o el ka que consideraban equivalente a $\mathrm{C}$ al final? ¿Por qué un signo que leían $\mathrm{P}$ en vez de alguno de los diversos que en la época barajaban para $\mathrm{V}$ ?

Baseŕbina (F.13.70) ${ }^{31}$ presenta la singularidad de que la lectura más evidente de los signos dañados previos es ] $\underline{\text { taekina }},{ }^{32}$ con un extraordinario parecido con la diosa Ataecina, documentada en la zona lusitana (especialmente en Extremadura) precisamente como Ataecina Proserpina. Por ello la lectura, factible, baseŕbina da un resultado muy llamativo, apoyado por el típico uso funerario del soporte, un kálathos. A los paralelos mencionados originalmente puede añadirse el espectacular kálathos de Elche de la Sierra en el que Eiroa ${ }^{33}$ aprecia una escena funeraria y señala la presencia de una divinidad alada que sería la típica diosa alada que encontramos con frecuencia pintada en cerámicas íberas en cuya discusión compara con Tanit, Ataecina y Proserpina.

24 Véase Ramos 2019, 268-272 y 330-349. La asimilación de Artemis a Tanit es bien conocida, siendo ambas diosas lunares. Las iconografías íberas de la diosa alada guardan gran similitud con el modelo de Artemis Ortia de Esparta y su representación en cerámica de otras ciudades griegas.

25 Cole 2004, 214.

26 Aunque no está claro que las cerámicas íberas que llamamos kálathos fuesen realmente equivalentes al término griego, en Grecia los kalathoi eran también una herramienta para el trabajo de la lana cuya forma adoptan los equivalentes cerámicos griegos. Quizás haya que plantearse la posibilidad de que el kálathos íbero reproduzca una herramienta de tejido, pero su uso al menos funerario es claro y la forma de "cesta" es polivalente.

Rodríguez Ramos 1995 b.

Simón 2009.

Argumento decisivo de falsedad para Almagro 2003, 321.

Hübner 1893, 146.

Rodríguez Ramos 1994.

Fletcher 1985, 16, lee [taegi]na : basetebina.

Eiroa 1986. 
El sentido psicopompo de una figura alada es muy conocido y aquí tenemos incluso un caballo alado, mientras que el carro podría ser el de la procesión funeraria. ${ }^{34}$

Dicho esto, los problemas. Son factibles las lecturas alternativas de Fletcher basetekena y de Untermann baseŕkena. El cuarto signo podría leerse te y no ŕ, aunque en este caso la forma te sería bastante extraña, mientras que el quinto puede leerse tanto ke como bi, con problemas para ambas lecturas. ${ }^{35}$ Pero la dificultad de la lectura no es casual, sino que se debe al extraño trazado de los signos de esta inscripción. Formas como la de s o el ŕ/te presentan rasgos paleográficos no sólo sin paralelos en las demás cerámicas pintadas de Liria, sino de cronología más moderna y mezclando formas de estilo cursivo con angulosas. Son grafías que apuntan a un post 150 a.C. y, aunque la s pudiera encajar con una simplificación ocasional del signo, la forma angulosa del ŕ/te es poco natural en una inscripción pintada. ${ }^{36}$ ¿Una última producción o un taller posterior similar? ¿Un pintor muy poco hábil escribiendo influido por los primeros estilos modernos sobre monedas o monumentos? Aunque por el tipo de pieza (pequeña y fragmentada; demasiado trabajo para tan poco material) y la época en que se encontró, sea poco probable, un hallazgo casual con términos y grafias extrañas siempre deja la sospecha de que se trate de una falsificación. Dejémosla pues en cuarentena.

\subsection{Neitin y iunstir}

Mucho se ha escrito sobre neitin y su aparición típica en la fórmula neitin iunstir. La cuestión es un tanto compleja por la variedad de contextos en que puede aparecer, incluso si la aparición de ambos en antropónimos (poco frecuente) no sólo no presupone problema alguno, sino que permitiría acotar su semántica.

Históricamente es importante reseñar la aportación al tema de Beltrán ${ }^{37}$ que, aunque intuitiva, todavía es defendible en muchos aspectos. Beltrán consideraba que el término iunstir tenía uso tanto en inscripciones sacras como profanas, para lo cual propuso un significado compatible que sería el de "adoración" respecto a dioses y de "saludo" respecto a personas. Esto último fue mucho más afinado por De Hoz, ${ }^{38}$ por paralelos

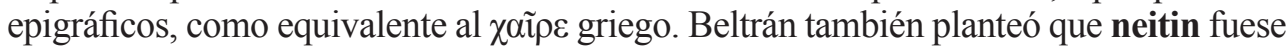
un teónimo, retomando la comparación con el dios Neton que ya hiciera Caro Baroja.

$\mathrm{El}$ hecho es que especialmente iunstir, pero también de forma equivalente neitin iunstir, se localizan en la cabecera/inicio de diversas inscripciones, especialmente plomos, pero también alguna cerámica posiblemente ritual y en roca o rupestres. En estos casos parecería independiente del texto principal y tratarse de una fórmula propiciatoria, sacra o apotropaica, que podría ser equivalente a los encabezamientos

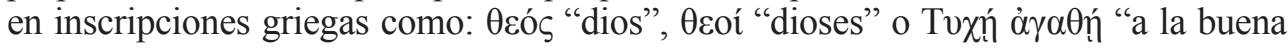

34 Véase también Ramos 2019, 336-337, identificándola con Core, que sería la asimilación de Tanit. Aunque la escena aquí remite a un sentido funerario, la iconografía típica de la diosa alada en cerámica íbera y terracotas remiten a la Artemis Efesia y Ortia como potnia theron (Ramos 2019, 333 y 348).

35 Untermann, a diferencia de Fletcher, no considera viable la lectura bi pero, aunque en su dibujo aparece un rasgo adicional que lo convierte en un ke perfecto, éste no aparece ni en las fotografías ni en el dibujo de Fletcher.

36 Rodríguez Ramos 1997, s-2, te-4 y ŕ-3. La forma más moderna, s-2, podría deberse a una trazo rápido cursivo de s-1 pero incluso así son formas raras a fines del s. III a.C. que sólo posteriormente se hacen normales (estilos Iberorromano 1 y 2) y contrastan con las grafías del resto de las cerámicas de Liria, típicas del estilo Neoibérico-2.

37 Beltrán 1974, 61.

38 De Hoz 1979, 236. 
(diosa) Fortuna". ${ }^{39}$ De forma similar De $\mathrm{Hoz}^{40}$ indica que podríamos estar ante una fórmula utilizable como invocación o saludo, que tal vez se tratara de la combinación "de un substantivo y un adjetivo al estilo de "buena fortuna"" ${ }^{41}$ Más recientemente Orduña ${ }^{42}$ compara la estructura neitiniunstir + NP-e con pro salute + NP, aunque falta por desarrollar cómo podría encajar esta equivalencia con el resto de su casuística. ${ }^{43}$

En lo que respecta a las apariciones de neitin sin iunstir, su uso en antroponimia (NEITINBELES) apenas proporciona información. Pero su principal valedor como teónimo viene siendo el monumento de Binéfar (D.12.1) donde, aunque podríamos entenderlo como el inicio de un antropónimo, la rareza del mismo como tal, su uso en la fórmula y su aparición precisamente en un gran monumento urbano hacen creíble la idea de una divinidad.

El caso de iunstir solo es totalmente distinto. En el inicio de plomos, aparte de la fórmula, puede encontrarse solo o tras antropónimo sin sufijo o sufijado por -te (¿agente?), ocupando una posición típica de predicado verbal. Esto es especialmente curioso porque se produce un paralelismo entre la estructura NP-(te) iunstir con neitin iunstir y, aunque la aparente equivalencia de los presuntos antropónimos tanto con sufijo como sin él ya es un enigma de por sí, al menos el que neitin nunca aparezca sufijado, apunta a que no tenga la misma función. ${ }^{44}$ Adicionalmente, si cuando vemos inicios de plomos en NP-(te) iunstir podemos recurrir a la hipótesis del saludo inicial de una misiva, idéntica estructura en la breve inscripción del pondus de Calafell ${ }^{45}$ aboga por un uso votivo.

El uso como "fórmula" incoativa (de saludo o lo que sea) tampoco puede aplicarse a sus apariciones dentro del texto. En Liria F.13.3 - una breve inscripción que tanto por su ubicación como por aparecer ekiar debiera tener un sentido de dedicatoria/ consagración- ambos términos aparecen tras sendos probables antropónimos sufijados por -te. Es decir, que podrían ser acciones complementarias típicamente asociadas a una consagración: hacer y iunstir. En F.13.28 sería una consagración similar donde a la ¿alografía? / ¿variante? unsir le precedería el dedicado con marca -er. Siguiendo su asociación a la marca de autoría ekiar los paralelos sugieren dos posibles valores para iunstir: "escribir"/"pintar" o "donar"/ "ofrendar". ${ }^{46}$ Pero, mientras que en los inicios en plomo encajaría a la perfección un "(esto) escribe" / "(esto) dice" (con amplios paralelos), tanto la alternancia con la fórmula, como sus usos aparentemente votivos (Cruzy, Calafell) apuntan a lo segundo.

Sobre plomo en posición no inicial destacan sendas apariciones de iŕika iunstirika (F.9.7 y C.1.24), ambas asociadas al verbo -ŕok-, pero sobre todo las múltiples apariciones en el conjunto de los tres plomos procedentes del ajuar de una tumba de Orleyl (F.9.5-7). En este conjunto son relevantes cuatro aspectos: el propio hecho de la repetición, la presencia de dos variantes en un mismo plomo (iunstir y

\footnotetext{
Rodríguez Ramos 2005, 58.

De Hoz 2011, 318.

Siguiendo esta interpretación puede sospecharse que De Hoz, con su habitual perspicacia, valoraba la posibilidad de que en la fórmula se usase un elemento equivalente a $\kappa \alpha \lambda$ ó o a $\alpha \gamma \alpha \theta$ ó $\varsigma$, idea que permite planteamientos interesantes. Orduña 2018, 425.

¿Iunstir = salve / שלום? ¿Neitin iunstir = "God save”? ¿Pero cómo explicar las repeticiones?

44 Más interrogantes añade la rupestre de Ger (Ferrer 2016) con un inicio neitin · basetíra · iunstir, donde el interpuesto basetiŕa recuerda formas verbales (Rodríguez Ramos 2000, 31 y 33; Orduña 2005, 115, 179 y 186).

45 Velaza 2002, 413-414.

46 Rodríguez Ramos 2000, 28-29, y 2005-06, 465.
} 
iunsir) testimoniando que no son alografías, el contexto funerario de la procedencia (que aboga por un sentido ritual) y la combinación iunsirmíi. ${ }^{47}$

La repetición del término en un plomo funerario o ritual de Orleyl sugiere que iunstir sea algo que se repite (en alusión a acción u objeto) compatible con tal uso. De los significados propuestos para iunstir ${ }^{48}$ el más compatible estaría en la órbita de "dar" / "ofrendar" / "consagrar". Es viable para una fórmula propiciatoria, pero para los inicios tras NP-te, aunque se podría imaginar una ampliación semántica compatible (tipo "enviar", por ejemplo), es lícito sospechar que estamos forzando demasiado.

Dicho esto, dada la dificultad de compatibilizar una fórmula apotropaica con tan variado testimonio, posiciones variadas y uso antroponímico, es interesante familiarizarse con los paralelos. Uno muy interesante se encuentra en la epigrafía árabe preislámica ${ }^{49}$ con la fórmula Waddum abum y variantes ( $w d m$ 'bm; 'bm $w d m ; w$-'bk $w d m ; w d$ 'b) con el sentido de "Waddum (es) padre / tu padre", ${ }^{50}$ que suele encontrarse encabezando inscripciones o especialmente al final (incluso de inscripciones funerarias), tanto integrada en el texto como en un aparte; puede encontrarse sola sobre amuletos de piedra o en contenedores cerámicos o incluso dentro de la inscripción indicando que el personaje tiene como padre al dios Waddum. Aparte de que el nombre ' $b$ "padre" es de uso común, también el nombre del dios puede aparecer independientemente ${ }^{51}$ y obviamente sendos términos son apropiados para uso antroponímico. Es quizás el paralelo más coherente con la extremada variedad de usos de neitin y iunstir y plenamente coincidente en suponer la inclusión de un teónimo.

\subsection{La presunta relación entre neitin y el dios Neton}

Este ha sido uno de los principales argumentos para suponer que neitin sea un teónimo, relacionándolo con la cita de Macrobio sobre el dios Neton de los accitanos (Guadix, Granada) y con inscripciones latinas dedicadas al mismo en Extremadura y sur de Portugal, para el que se suele aceptar una etimología celta y una relación con el presunto dios de la guerra Néit. Planteado en múltiples ocasiones, su última formulación se debe a Almagro, ${ }^{52}$ quien añade el elemento de la identificación

47 Menos decisivo es el compuesto iunstirlaku puesto que podría finalmente interpretarse como un antropónimo. Pero resulta llamativo que, siendo poco frecuente su uso onomástico, apareciera justamente aquí entre tantos iunstir; mientras que la comparación con el segmento iunstir lakunḿiltiŕte del mismo plomo resulta curiosa. ¿Podría tratarse de un cargo público (¡iltiŕ!)? ¿De una función sacerdotal?

48 No he entrado a valorar propuestas cuya compatibilidad con los datos es más que discutible, como el 'licet' de Untermann.

49 Para la correcta evaluación de éste y otros paralelos orientales conviene recordar que, aunque la relación no sea tan directa como en el método de desciframiento del "principio dei testi paralleli" (Pallotino 1984, 435), que tanto éxito ha demostrado para el etrusco, puesto que la afinidad cultural no es tan grande, sí nos permite hacer una mejor idea de los posibles usos y contenidos con más base que las especulaciones desde la perspectiva actual o incluso que las comparaciones que a veces se efectúan con hábitos romanos de época imperial correspondientes a una sociedad mucho más compleja. Por otro lado, estas inscripciones árabes, algunas contemporáneas a las íberas, son herencia de la tradición alfabética fenicia, que sí tuvo impacto en la cultura íbera y a la que no tenemos acceso directo.

50 Jamme 1966, 15 y 77-78; Nebes 2010, 187.

51 Por ejemplo en la base del Corpus of Sabaic Inscriptions (CSAI) dentro del DASI puede encontrarse sólo o con el posesivo $l$ - en objetos diversos (contenedor SAM 16; bloque de piedra DhM 199; pendiente de bronce DhM 367). DASI = Digital Archive for the Study of pre-Islamic Arabian Inscriptions (http://dasi.cnr.it/index.php) [consulta 19-IX-2019].

52 Almagro 2002. 


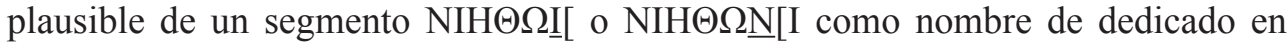
dativo sobre una inscripción en cerámica de Huelva del s. VI a.C., concluyendo que es el mismo dios, con misma etimología celta, pero tartésico. La hipótesis en su conjunto ha sido repetida en numerosas ocasiones, pero no se ha hecho una crítica, muy necesaria, pues presenta diversos puntos débiles.

En primer lugar la última pieza: la forma del presunto teónimo de Huelva no encaja con ninguna de las etimologías célticas propuestas. Ni el conjunto vocálico $\mathrm{IH}$, en vez de -ey-, ni la aspiración de la dental $\Theta$. Sospechosamente los mejores paralelos estarían en el irlandés medieval, diferenciándose de las formas celtas e indoeuropeas. En estas condiciones cabe preguntarse si el "parecido" fonético realmente justifica su interpretación como teónimo y su identificación con Neto.

En segundo lugar el carácter íbero de Neton: más allá de que en inscripciones de la zona (como H.1.1) cuesta identificar la lengua como íbera, Acci es una fundación con reasentamiento de una legión vernácula ${ }^{53}$ que bien podría ser lusitana. Dado que esta conexión sería el mejor argumento para la relación neitin / Neton, su cuestionabilidad le supone un serio problema.

En tercer lugar la explicación etimológica de Neton. Independientemente de si el teónimo es indoeuropeo o no, hay que notar que las interpretaciones alegadas presentan contradicciones y puntos que deben ser matizados.

El alegado dios de la guerra Néit no es un dios bien documentado, sino un personaje de las leyendas irlandesas (uno de los invasores fomoré) que el glosario Cormac (Sanas Cormaic), un texto cuya primera versión es del s. IX y que intenta explicar términos difíciles, define (con diversas grafías Néit, Neit, Ned, Neid) ${ }^{54}$ como un dios de la guerra entre los gentiles celtas, esposo de Neimham. La cual es una de las tres principales diosas de la guerra, aunque más bien una furia.

De las etimologías indoeuropeas se vienen repitiendo las mismas referencias al viejo diccionario de Pokorny, ${ }^{55}$ sin percibir ni su antigüedad ni los puntos problemáticos expresos en el mismo. Se señala que Pokorny (IEW 760) explica Néit y el a.ir. niath "guerrero" con las raíces *ney-1 "liderar" y *ney-2 "brillar". Hay diversos problemas. Primero: se ha de ser consciente de que el antiguo irlandés es una lengua celta fonéticamente muy innovada, de modo que cuando no hay un paradigma claro un mismo término admite explicaciones etimológicas diversas y diferentes. Segundo: para la conexión de ambos términos con el irlandés Pokorny parte de una forma *neitos; es decir un tema en -s, no en nasal, y por tanto distinto a Neton. Tercero: puede encontrarse que Pokorny propone una tercera etimología para las mismas formas irlandesas (*nant IEW 755) que no sólo es incompatible con Neton, sino que es justamente la que se prefiere en trabajos más recientes. ${ }^{56}$

Añádase a ello el que, si consideramos que la forma de la raíz es *ney-, una etimología debiera explicar el sufijo -ton y que, dado que las formas deverbales en -to- tienen sentido pasivo, no parece apropiado. Preferiríamos un sufijo de nomen agentis -tor, pero no lo tenemos. ${ }^{57}$

53 González Román 2002, 159-160.

54 Early Irish Glossary Database: entrada manuscrito Yellow 965 https:/www.asnc.cam.ac.uk/irishglossaries/texts. php?versionID $=9 \&$ page $=20 \&$ perPage $=50$, concordancia de variantes https://www.asnc.cam.ac.uk/irishglossaries/ concordances.php?main=9\&cpFamily=sc\&display=fulltext\&readingID=17959\#17959 [acceso 18-IX-2019].

55 Pokorny 1959-1969; en adelante IEW.

56 Matasović 2009, 283, reconstruye el proto-celta *nanti, "battle" (subst.), desde el PIE *nent- "fight".

57 Es decir, no es lo mismo victus que victor. Pokorny plantea para *ney-2 una variante con sufijo -t- basada en lat. 
En definitiva, las comparaciones con Neton no pasan de ser una hipótesis posible pero incierta; de modo que la propuesta de que neitin sea un teónimo se apoya algo en la excepcionalidad del monumento de Binéfar, pero sobre todo en su uso en una fórmula aparentemente apotropaica.

\section{Las fórmulas votivas en Liria}

Las fórmulas votivas en la cerámica pintada de Liria parecen presentarse sobre todo en la parte superior (como el borde-ala plano) separadas de la decoración y han sido especialmente estudiadas por Silgo ${ }^{58}$ a partir de la interpretación de -e como dativo, pero desconociendo su variante -er. Como teónimos nos interesa más lo que Silgo (basándose en fantasiosas interpretaciones vascoiberistas) considera epítetos: los términos acabados en betan / bitan: benebetan-er (F.13.12 y 28), tolirbitan-e/-er (F.13.5 y 27) y lokumbetan-e (F.13.43). Es decir, que tendríamos tres menciones divinas con el denominador común betan, lo que hace verosímil que sean tres compuestos en los que el segundo elemento tuviese un sentido similar a "dios", "divino" o "espíritu”. 59

Resumiendo lo estudiado en Rodríguez $\operatorname{Ramos}^{60}$ y NIC 42, es llamativa tanto la comparación con el teónimo BETATVN (vide supra) como con los nombres de las cordilleras de zona íbera Idubeda y Orospeda, puesto que semánticamente son compatibles con tener una mención a una divinidad o por el mero concepto de elevación. Pero para los paralelos es un problema determinar la sonoridad o no de la dental. Leyendo como duales las inscripciones edetanas habríamos de leer ${ }^{\mathrm{e}=\mathrm{d}} \mathbf{b e d a n}$, pero, como hemos indicado, esa lectura dista mucho de estar fundamentada. En inscripciones duales tenemos el plomo de Ampurias (C.1.24) con un CTO 'tuŕrgosbetan, pero también un curioso dinebedan, cuyo inicio no encuentra paralelos adecuados como para clasificarlo como CTO, pero que no deja de recordar a los presuntos teónimos de Liria. ${ }^{61}$ Otros contextos favorables a la interpretación religiosa de betan/bitan serían la árula de Tarragona C.18.7, ${ }^{62}$ el amuleto colgante de Can Gambús ${ }^{63}$ y el monumento de Binéfar (D.12.2). ${ }^{64}$

niteo, pero véase Matasović 2009, 288.

58 Silgo 1994, 64, 191-192.

59 Posteriormente el sentido religioso de los textos de Liria ha sido defendido en Rodríguez Ramos 2005b, mientras que recientemente la cuestión ha sido objeto de revisión por Beltrán Lloris 2014. También Ferrer 2018a, 114, asume que las inscripciones de Liria son probablemente votivas, aunque su exposición, defendiendo el carácter teonímico de tolirbitan y benebetan, se ve seriamente perjudicada por la ausencia de referencia a las propuestas de Silgo 1994, de Orduña 2005, 210, 228-229 y 313-314, o a NIC 42.

60 Rodríguez Ramos 2017, 134-136.

${ }_{61}$ Aunque apreciaríamos una marca -e u otro contexto más claro, sí resulta interesante que se encuentra poco antes de iŕrika iunstirika. El parecido con el Zeus etrusco (Tin) es seguramente coincidencia, aunque no está de más recordar que en Cataluña el comercio etrusco tuvo una presencia significativa en el s. VI a.C.

62 Toŕs/ in/ bita donde podría entenderse tanto que toŕsin (NIC 159) es el teónimo como que toŕsinbita(n) es el dedicante.

63 Artigues et alii 2007.

64 También merecen atención la secuencia kaisurarbitan (donde lo que antecede parece un genitivo -ar de kaisur; cf. NIC 73) y la posible reconstrucción del hiato de ḿbaŕbianer como un dativo ḿbaŕ bi(t)an-er en la fusayola de Oliete (Rodríguez Ramos 2017, 135). 


\section{El monograma de ka(uŕ)ko-(ŕ)}

Los estudios de Ferrer ${ }^{65}$ sobre la aparición de dos monogramas en el Abrigo del Tarragón, en lo que geográficamente podría ser el límite occidental edetano antes de las montañas al oeste de Liria y Casinos, con los textos kauŕkobeŕole y kaukobeŕole, en su comparación con el monograma de la cerámica pintada de Liria F.13.3 kaŕkoelole, han confirmado la propuesta de Rodríguez Ramos ${ }^{66}$ de ver en el kaukoŕ de tres inscripciones del santuario de Montaña Frontera (un pedestal, un bronce y un kálathos) el nombre de un dios, que quizás se encontrara en el topónimo Caucoliberi. ${ }^{67}$

Ferrer ${ }^{68}$ compara el texto con la fórmula neitin iunstir y la parte beŕole con las formas verbales de eŕoke, sugiriendo que sea un teónimo con un verbo. Con todo, está claro que el uso de sendas fórmulas sería totalmente diferente, dado el aislamiento de ésta en el monograma. Es interesante constatar que, como señala Vizcaíno, ${ }^{69}$ en Liria -además de en F.13.3- aparece también un pseudo-monograma en la decoración de F.13.5, también en forma de rueda o asterisco, pero con signoides; estando en ambos casos delante de imágenes de guerreros a caballo. Si tenemos en cuenta que en la propia F.13.3 delante de otro caballo se ha detectado un texto onomatopéyico del relincho, no sería imposible considerar que el círculo sea una expresión del jinete, lo que encajaría con considerarlo una oración/invocación, idea muy apropiada para su uso rupestre.

Es cierto que no sería imposible proponerle un análisis como compuesto antroponímico. Sería comparable con el poco frecuente kaŕko (NIC 79) y el posible beloŕ (NIC 35) que, con un hipotético dativo, quedaría como kaŕkobeloŕ-e. En tal caso, dada la individualización de un dios kaukoŕ / kauŕko, seguramente preferiríamos ver en beloŕ una adjetivación que ensalzara algún aspecto de la divinidad. Es plausible, por más que, de ser así, extrañaría tanto la variabilidad de las formas, como que la presunta adjetivación sólo aparezca en el monograma.

Lo que sí resulta realmente sorprendente del monograma es que, como tal, debiera ser una entidad gráfica reconocible y, sin embargo, admite una gran variabilidad fonética y gráfica; así como que el pintor de F.13.5 conocía su existencia, pero no sabía más que hacer una mala imitación. Incluso aunque atribuyéramos a la estructura del monograma una preferencia por usar sólo 8 letras (con 9, una queda desemparejada) esto podría explicar como mucho la variación kaŕko / kauŕko / kauko. Adicionalmente, ese aparente desplazamiento de ŕ entre kauŕko y kaukoŕ resulta sorprendente, por más que es cierto que en la -ŕ final no es descartable un problema de lectura y segmentación.

Por otra parte, aunque Ferrer ${ }^{70}$ presenta como normal en íbero la caída de la b de beŕole, la realidad dista de ser tan clara y la referencia que da no justifica su uso, puesto que ésta se limita a casos ante vocal posterior. ${ }^{71}$ En efecto, los únicos casos

\footnotetext{
Ferrer 2018b, 238-243.

NIC 154.

En este caso el interés está en el parecido entre el liberi del topónimo y el que la asimilación romana de la divinidad de Montaña Frontera sea el Liber Pater.

Ferrer 2018b, 251.

Vizcaíno 2015, 73-74.

Ferrer 2018b, 247.

Quintanilla presenta las leyendas monetales neronken y bolśken y como posible la alternancia entre los formantes oto / Bodon y explícitamente hace referencia al fenómeno ante vocales posteriores al compararlo con la fonética vasca (Quintanilla 1998, 269).
} 
bien documentados son ante $\mathbf{u}$, dada la extrema rareza del silabograma, y ante $\mathbf{o}$, para los que hay algunos ejemplos claros aunque no muy numerosos. Ante vocales no posteriores no hay nada claro, más allá de alguna comparación hipotética y alguna alternancia que parece morfológica. Es más, siendo tan frecuentes los formantes onomásticos iniciados en b- y precisamente en be-, de ser algo realmente normal tendríamos una clara serie de formantes paralelos con o sin b-. Es decir, no es una caída normal. ${ }^{72}$ Tampoco son frecuentes esas series homo-consonánticas, en especial elole; lo que, por otra parte, podría sugerir explicar las formas con eŕole como disimilación.

Así tenemos una extraña hipervariación en las formas documentadas, tanto en el probable teónimo como en la forma acompañante. Salvo que seamos víctimas de una documentación por azar muy distorsionada, las posibilidades más obvias serían las siguientes: 1) la fórmula tiene un fuerte componente oral repetitivo, con cierta "vida propia" como expresión hecha o de escasa relación con el léxico normal íbero (que por analogía hubiese estabilizado las formas); 2) los términos tienen un carácter de préstamo onomatopéyico o exógeno reinterpretado.

Del presunto teónimo sería difícil pensar en una onomatopeya $y$, aunque sería fácil hacer una explicación plausible como préstamo de deidad alóctona, paralela a la de Almagro para neitin / Neto, comparándolo con el mítico Gargor-is, sería a todas luces prematuro.

Del otro segmento, elole / beŕole, sí se puede sospechar más. En primer lugar expresiones onomatopéyicas de sonido similar usadas, a veces en rituales, pero especialmente como grito de guerra, tales como en griego $\dot{\varepsilon} \lambda \varepsilon \lambda \varepsilon \tilde{v}, \dot{\alpha} \lambda \alpha \lambda \alpha$ o la ỏ $\lambda \circ \lambda v \gamma \eta ́$. Esto sería muy aplicable si tenemos en cuenta las apariciones del monograma en las cerámicas de Liria delante de jinetes armados al galope: una invocación al dios con un grito de guerra.

Por otra parte, un término similar se encuentra con uso ritual en diversas lenguas semíticas. Así en hebreo tenemos el verbo הלל glosado por Gesenius ${ }^{73}$ como "rühmen, preisen", "m. Akk. (eine Gottheit) preisen" y para el que menciona diversos paralelos interesantes: acadio alālu, "ein Freudenlied singen", árabe halla, "jubeln, jauchzen”, o siriaco hallel, "preisen". La forma no es sólo idónea para una invocación propiciatoria o una oración, sino que la íbera sería perfectamente paralelizable a la hebrea הַלְלוּ יָה (en griego $\dot{\alpha} \lambda \lambda \eta \lambda$ ovḯ), "lobt Jahwe", donde el final -yah es un apócope de Yahweh. El uso de este tipo de forma podría haber venido por vía de la colonización fenicia y, según esa interpretación, la fórmula del monograma podría recoger una invocación al dios kauŕko.

Naturalmente, aunque esta interpretación encajaría perfectamente con el monograma usado como una oración tanto en la boca de los guerreros que van a la batalla como en un santuario rupestre, no es más que una hipótesis. En todo caso, lo interesante es constatar que en diversas religiones del Mediterráneo un sonido de ese tipo tenía un uso ritual/invocativo y que, por ende, no sería extraño encontrarlo también en la religión íbera.

\footnotetext{
72 Existe un estudio reciente sobre el tema de la caída de b- inicial (Rodríguez Ramos 2018, 193-198) donde se examinan más casos posibles y expresamente la posibilidad de encontrar alternancias ante e, pero estas son inciertas y muy minoritarias.

73 Gesenius 2013, 278-279.
} 


\section{Las inscripciones rupestres}

Aunque desde hace años se ha venido defendiendo el carácter votivo de las inscripciones rupestres íberas e incluso se ha propuesto identificar algún teónimo, recientemente Ferrer ha hecho diversos intentos de identificar posibles nombres de dioses. Ya hemos tratado el tema del monograma elolekaŕko. Aparte de éste los principales criterios que plantea Ferrer para las rupestres son dos: la repetición de un mismo término (con atención especial a los casos en que aparece aislado) y la existencia de unos finales que considera serían propios de nombres de dioses, principalmente -er y -al.

Cabe advertir que, aunque hay buenos motivos para considerar la presencia de inscripciones votivas en las rupestres, en aquellos parajes donde se documentan muchas sobre este tipo de soporte, la función y el contenido de las mismas pueden ser muy variados. Un ejemplo obvio lo tenemos en la rupestre latina de reciente aparición con el nombre de cuatro magistrados, ${ }^{74}$ cuyo uso podría ser en el mejor de los casos mágico (o no), pero que desde luego no incluye a ningún dios. En el Próximo Oriente, en entornos con inscripciones rupestres se aprecia una gran diversidad ${ }^{75} \mathrm{y}$, junto a un gran número de marcas de autor del texto o de dibujos, pueden hallarse diversas fórmulas de oraciones (incluidas con el sentido in memoriam) e invocaciones rezando a tal dios para que le otorgue una gracia, maldiciones, inscripciones sepulcrales, pero incluso pueden encontrarse anotaciones diciendo que fulano acampó allí, o que llevó los rebaños ${ }^{76}$ referencias incluso de haber encontrado un texto que grabó un familiar muerto, ${ }^{77}$ no siendo escasas las expresiones amorosas, algunas tan expresas que indican que allí practicó sexo con tal o cual persona. Estas últimas inscripciones suelen tener un nombre o dos con un verbo $n y k / n k \cdot{ }^{78}$ Obsérvese que es una estructura muy similar a un texto votivo con léxico repetido, pero totalmente profana.

Incluso para los casos supuestamente claros de repeticiones de términos aislados los mismos trabajos de Ferrer muestran contraejemplos. Así el término kutur se repite en diversas inscripciones rupestres y no rupestres, pero incluso es texto único en una: ${ }^{79}$ por lo que, si no conociéramos el término, sería otro candidato a teónimo.

Más crítico hay que ser con el planteamiento de Ferrer de que habría que buscar una marca que diferencie teónimos de antropónimos. ¿Por qué ha de existir tal indicador? Parte del problema radica en una explicación confusa, en ocasiones contradictoria, y con una terminología inadecuada, lo que hace imposible resumirla sin una cierta exégesis.

El caso es que Ferrer en $2015^{80}$ todavía plantea artiunaner como antropónimo, considerando que -er sería parte del mismo según el modelo (por lo demás dudoso)

44 Ferrer et alii 2018, 176-185.

75 El análisis de los tipos de contenido de las inscripciones hismaicas (árabe septentrional antiguo) de Wādī Judayyid (Jordania) de la excelente tesis doctoral de King 1990, 52-74, donde se estudian 1337 novedades epigráficas, puede dar una idea de la variedad temática. La autora incluye al final un pequeño muestrario de tipos de contenido de inscripciones hismaicas que no se documentan en Wādī Judayyid.

76 Por ejemplo http://krc.orient.ox.ac.uk/ociana/corpus/pages/OCIANA_0003303.html. Base de datos OCIANA (Online Corpus of the Inscriptions of Ancient North Arabia http://krc.orient.ox.ac.uk/ociana/) [consultas de 30X-2019].

77 http://krc.orient.ox.ac.uk/ociana/corpus/pages/OCIANA_0002929.html.

78 King 1990, 69-70.

79 Ferrer 2018, 28.

80 Ferrer 2015, 16. 
de SANIBELSER. Sí que menciona okale como un caso de sufijo -e planteando que puede dudarse si es antropónimo o teónimo. ${ }^{81}$

Es en 2016 cuando Ferrer, ${ }^{82}$ a partir de la consideración de la repetición de urtal, ${ }^{83}$ empieza a plantearse buscar otros teónimos y ya considera que śauśir podría ser tanto antropónimo como quizás teónimo. ${ }^{84}$ Ello no obstante, en $2017^{85}$ todavía mantiene que "le morpheme er pourrait être une caractéristique des noms de divinités" 86 y presenta a partir de urtal y okal el que el final en -al fuese otro marcador que es parte de la formación del nombre. ${ }^{87}$

El "morfo" 88 o "final" -er como "marca morfológica" identificadora de teónimos frente a antropónimos se convierte en el tema central de un artículo de Ferrer en $2018,{ }^{89}$ pero su planteamiento es bastante ambiguo. No indica que pudiera ser sufijo marcador de dativo, ni que pudiera ser una marca de caso, ni se menciona el planteamiento de Orduña, que en su caso sería referencia inexcusable. Aunque del análisis que presenta ${ }^{90}$ de lo que define como elementos que "es caracteritzen per combinar amb el morf -er" se entiende que los considera sufijos (de la clase que sea) que se añaden al teónimo y, de modo similar, podría deducirse entre líneas cuando sugiere que quizás también el "morf e" pudiera servir para identificar a las divinidades; ${ }^{91}$ no sólo es que nunca se define, sino que cuando ejemplifica los casos del "morfo" en antropónimos se trata inequívocamente de parte del substantivo. ${ }^{92}$ Es

81 Ferrer 2015, 15.

82 Ferrer 2016, 19.

83 Ferrer transcribe repetidamente este segmento como dual urdal. Sin embargo, no hay datos internos que justifiquen que aparezca en una inscripción dual y su argumentación es circunstancial y vascoiberista.

84 Ferrer 2016, 25.

85 Ferrer 2017, 12.

86 "Bien que dans les articles précédents je considérais comme alternative principale qu'artiunaner ou artiunan soient des noms de personne, il faut considérer comme alternative principale que ce soit un nom de divinité, car le morphème er pourrait être une caractéristique des noms de divinités" (Ferrer 2017, 12).

87 Ferrer 2017, 12, y 2019, 53. "Si le rapport d'urdal avec la divinité vascone VRDE (Velaza 2012) était correcte, urdal pourrait être le résultat de la composition *urde + al, ce qui permettrait de penser que okal est le résultat de la composition de oke ou oka + al" (Ferrer 2017, 12). Da como ejemplos urdal, okal, tikanal, egibal y quizás edagardal. Añade también el término de los plomos aŕikal, para el que propone una etimología vascoibérica "roble". Debo decir que conociendo los contextos de aŕikal soy muy escéptico respecto a su identificación como teónimo.

88 De cara al lingüista que espera rigor terminológico cabe advertir que muchos iberistas han adoptado el término "morfo" para referirse a cualquier segmento breve sin valorar lo que es. En la práctica para esos "morfos" plantean valores no sólo de afijos, sino de pronombres, artículos, verbos e incluso numerales. Así se entenderá mejor que se hable de "morfo", pero nunca se mencione ni al morfema que representa ni el tipo del mismo. En mi opinión es un uso confuso que debiera evitarse.

89 "Una possible solució [para diferenciar teónimos de antropónimos] seria identificar alguna marca morfològica que almenys a les inscripcions votives fos exclusiva dels teònims i els diferenciés dels antropònims. En aquest treball s'avalua la possibilitat que el morf -er sigui aquesta marca" (Ferrer 2018a, 103).

90 Ferrer 2018a,121-122.

91 Ferrer 2018a, 118. Pero esta interpretación se ve contradicha cuando indica que -er no sería una variante de -ar y pone al mismo nivel que -er y -e los finales -al / aŕ que en dicho artículo sigue presentando como parte integrante de los teónimos (Ferrer 2018, 121).

92 Esto es independiente del hecho de que sus análisis onomásticos presentan problemas serios, con bastante de ad hoc, y cuando menos tendría que justificarlos y dar referencias. Por ejemplo, no hay más argumentos objetivos para segmentar baiser en bais-er que la conveniencia argumental y no se indica al lector que no es el análisis estándar. En todo caso, bastan las inscripciones latinas de sus ejemplos (SANIBELSER nominativo, TANNEPAESERI dativo) para ver que -ER, incluso aunque se quisiere segmentar como morfema (lo que dista de ser obvio), forma parte del substantivo. 
evidente que no puede ser lo mismo un sufijo que se utilice para formar substantivos (o un segundo formante de compuesto), que un sufijo flexivo, pero Ferrer no sólo no aprecia contradicción alguna, sino que razona asumiendo que efectivamente es el mismo "morfo" tanto en teónimos como en antropónimos.

Es sólo después de la publicación del estudio de las marcas de dativo de Rodríguez Ramos $^{93}$-en el que se apoya la idea de Orduña de que tanto e como er son marcas de dativo y se estudia su uso con teónimos, así como se plantea la variante de er en irque Ferrer ${ }^{94}$ hace una presentación más coherente de las sufijaciones de los candidatos a teónimo, indicando (sin referenciar los precedentes): que el sufijo -e, para el que ya antes había supuesto un valor de dativo, "és el millor candidat a ser el morf que identifica la divinitat” y que -er e -ir quizás serían variantes del mismo.

Dados los datos parece aceptable considerar que varios de los términos acabados en -e, -er e -ir en las inscripciones rupestres pueden corresponder a divinidades; si bien esto dependerá también de la seguridad de la segmentación y del análisis sintáctico global. Su mejor interpretación es como morfemas de marca de caso (como mínimo de benefactivo), utilizable tanto con divinidades como con personas sin que ello suponga problema alguno, amén de otros posibles usos. ${ }^{95}$ Las interpretaciones propuestas por Ferrer sobre finales en -ir vendrían a apoyar la hipótesis previa de Rodríguez Ramos, ${ }^{96}$ especialmente en su apariencia de dialectalismo regional.

Por otro lado, es interesante la identificación que hace de alguno de los segmentos sospechosos no sólo con final -e, sino seguidos de barras numerales en el sentido de tanta cantidad para X que, como señala Ferrer, al no indicarse el objeto, se trataría de ofertas implícitas. Esto es un tanto extraño, como lo es el que no se mencione al oferente si es que es una inscripción votiva; aunque recuerda un poco a aquellas inscripciones griegas donde lo que se indica no es la ofrenda que se ha hecho, sino cuál es la ofrenda correcta a hacer en tal sitio. Así podría plantearse un sentido de "(aquí el oferente) al dios Fulano (le ofrecerá) dos". ${ }^{97}$

Por lo demás, visto que la correcta interpretación de los sufijos -e/-er /-ir es sintáctica, esta explicación no parece extrapolable ${ }^{98}$ para el otro segmento que Ferrer presenta como marca identificativa de nombres de dioses, -al, haciendo hincapié en que precisamente es un final infrecuente en íbero ${ }^{99}$ y que por eso sería una marca especial.

El problema es que Ferrer no aclara cuál se supone que tendría que ser el sentido lingüístico ni la categoría gramatical de esa supuesta marca de teónimos -al. Igualmente inconsistente es que se arguya a favor de tal propuesta el que los finales en -1 son raros en íbero, como si esta rareza justificara un uso específico con teónimos. Cuando un fonema es raro en una posición en una lengua es por una causa

\footnotetext{
Rodríguez Ramos 2017.

Ferrer 2019, 50-51.

Esto se aplica también a que, incluso si aceptáramos el análisis que Ferrer plantea para aŕikal-, éste podría estar perfectamente refiriéndose a un cargo o función de una persona. Sin pretender que sea ese el significado, compárese con anotaciones del tipo "(páguese) al portador" o "(el prestatario abonará) al prestamista".

Rodríguez Ramos 2017, 140-142.

97 Un paralelo rupestre paleohispánico lo tendríamos en el inscripción lusitana L.3.1

98 En especial por admitir la sufijación -e o -er, para lo que el mejor ejemplo es okal-, puesto que los otros propuestos por Ferrer 2019, 50-51, ekibal, tikanal y aŕikal son menos claros.

99 Ferrer 2018a, 113.
} 
concreta y lingüística. Por lo tanto, un hecho singular nos debiera conducir a una explicación precisa.

Una posible explicación sería que se tratara de un fenómeno local, dialectal en el sentido amplio de la palabra. De esa forma, en algunos dialectos ¿rurales? / ¿interiores? podría ser mucho más normal un final en -l, que en otras zonas fuesen substantivos acabados en -r. ${ }^{100}$ Aunque depende de que el muestreo "accidental" no nos haya dado una representación desafortunada (y ésta no es una posibilidad que deba despreciarse a la ligera), en principio parece improbable, por lo que explica Ferrer de la coincidencia en términos sospechosos de teonimia.

Si efectivamente la presencia de -al no es una coincidencia (lo que por motivos metodológicos en primera instancia debiéramos descartar), la explicación íbera más obvia es que fuese un formante de compuestos con un significado similar a "dios", como hemos visto para betan. Sin embargo, hasta donde sabemos, un formante en posición final con estructura VC resulta extraño. Incluso si supusiéramos la caída de una consonante para normalizarlo ('al' $<*$ Cal), los 'sandhis' que produce son peculiares al basarse en la crasis vocálica casi siempre: ${ }^{101}$ urtal $<$ urtV-al; okal < okV-al; ekibal < ekibV-al; kartal < karte-al; aŕikal $<$ aŕikV-al; con la única forma normal tikan-al. Por no hablar de que varios de los análisis suponen una resultante bisilábica tras hacer perder al primer formante una sílaba. Sea como sea, muy extraño.

Otra posibilidad teórica - pero, con los datos actuales, muy ad hoc-sería que todos los teónimos procedieran de compuestos muy antiguos fosilizados en una fase protoíbera y que, por su naturaleza expresivo-ritual, hubiesen mantenido la -1 final. Lo mejor que se puede decir de esta opción es que imposible no es.

Respecto al final atípico, si dejamos de lado las opciones dialectales, existen $a$ priori dos opciones. Una primera es que fuese un sonido onomatopéyico, que en este caso pudiera ser similar al "oh" invocativo; ${ }^{102}$ pero parece improbable dado que al -al le pueden seguir los casos -e y -er. La segunda es la típica en estos casos cuando una lengua presenta términos inusuales por fonética o estructura: que sea un adstrato, es decir, un préstamo. ${ }^{103}$ Este análisis es bien conocido para el estudio del vasco, donde términos con estructura atípica o inicios en consonantes que la lengua vasca ha perdido (como en $\mathrm{t}$ - o en $\mathrm{k}$-) son sospechosos de no ser patrimoniales y efectivamente suelen acabar teniendo una explicación latina o romance.

\section{Los posibles teónimos y sus paralelos alóctonos}

De los paralelos alóctonos cabe mencionar en primer lugar la cuestión aquitana. Desde hace años pueden encontrarse comparaciones con el íbero especialmente de

100 Como baikar, kutur, seltar o śalir. Como los finales en $\mathbf{r}$ en íbero son muy frecuentes no es absurdo suponer que deriven de una neutralización entre varios fonemas, lo que explicaría la escasez de $\mathbf{l}$ final.

101 Naturalmente no son reconstrucciones, sino ilustraciones a partir de lo propuesto por Ferrer.

102 Existen paralelos, por ejemplo, en la epigrafía árabe preislámica, como en inscripciones donde existe la fórmula ' $\mathrm{h}+$ nombre del dios $1+$ nombre de persona' donde la ' $h$ ' inicia la oración en la que se pide un favor al dios para la persona. Así en la base de datos Ociana: KJA $348 \mathrm{hlhm} l \mathrm{lt}$, KJC47 h hlm l hbb l.

103 "Words which violate the typical phonological patterns (canonical forms, morpheme strucutre, syllabe structure, phonotactics) of a language are likely to be loans" (Campbell 1998, 64). 
antropónimos, pero también de algún teónimo nativo de las inscripciones latinas de Aquitania. Sin embargo, aunque el aquitano sí muestra una buena lista de conexiones con el vasco, hasta el punto de ser considerado vasco antiguo, su relación con la lengua íbera no resulta tan clara. Pueden encontrarse algunas conexiones notables (como BELES o BAISER), pero también diferencias, especialmente relevantes las que corresponden a léxico básico del vasco pero que no encuentran coincidencia alguna en lo íbero. También desconocemos el grado de iberización cultural en la zona de las inscripciones aquitanas, que pudo ser responsable de algún préstamo léxico o religioso. Sea como sea, a día de hoy, entre las diversas equiparaciones que se han planteado posiblemente la única interesante sea la de Siles ${ }^{104}$ comparando tolirbitane con el dios HERCVLI TOLI ANDOSSO.

Por otra parte, quizás no sea casualidad la falta de una correlación clara entre los teónimos aquitanos y las inscripciones íberas, incluso si ambas lenguas tuviesen una relación genética estrecha. ${ }^{105}$ De un lado, el número de divinidades de las inscripciones aquitanas es muy amplio, lo que apunta a un politeísmo con muchas divinidades locales o menores. De otro, en los paralelos del léxico vasco con los teónimos aquitanos destacan las conexiones con términos para animales y plantas. Pese a algún posible faux ami, la impresión es de un culto a elementos naturales próxima al animismo. Es muy dudoso que fuera así el tipo de religión que esperaríamos para una cultura como la íbera, urbana, orientalizante y, como mínimo, proto-estatal. ${ }^{106}$ Como en todos los cambios religiosos, suele haber un mayor conservadurismo en los ámbitos rurales (recuérdese la etimología de "pagano"), por lo que quizás se encuentre más coincidencia en inscripciones como las rupestres.

La otra posible conexión es la de importación de cultos, dentro del fenómeno orientalizante, con paralelos desde la propia Grecia hasta -especialmente- Etruria, del que, como hemos visto, tenemos testimonio expreso en Estrabón respecto a Artemis. De hecho, merece enfatizarse que, dado que en la antigüedad los dioses se usaban como garantes del cumplimiento de pactos, la disponibilidad de una divinidad común era casi una necesidad para poder establecer relaciones comerciales.

La primera candidata obvia sería la propia Artemis. El único término parecido es artiunan, que hemos visto que parece ser una divinidad, pero, aparte de que su parecido es discreto, parece un lugar un tanto distante. Hay sin embargo dos indicios favorables. El primero es que Artemis era una diosa agreste con especial relevancia en marcar fronteras y puntos de tránsito, aspectos que concuerdan con los pasos de la Cerdaña. El segundo es su aparición ante el término tanito con un parecido un tanto engañoso con Tanit (sobre el que volveremos más tarde) y que es precisamente la equivalente púnica a la Artemis griega.

Más interesantes son los paralelos púnicos, en los que obviamente se ha buscado la comparación con Baal. Así Lillo, ampliando una idea de Sanmartín Ascaso, ${ }^{107}$ criticaba la comparación de beleś y bels con el aquitano, sugiriendo su relación

104 Siles 1985, 294.

105 Sobre la relación entre vasco e íbero véase Rodríguez Ramos 2002 y Orduña 2019. La cuestión suscita un excesivo apasionamiento en uno y otro sentido, pero no es tan interesante. Más importante que afirmar que se relacionan o que no (lo que parece ser el Santo Grial para algunos), es comprender cómo; sólo la comprensión dará sentido a la respuesta, que sin ella no es más que un saber inútil.

106 Abunda en el mismo sentido de lo aquí argumentado la presencia en antropónimos de formas equiparadas con términos básicos del léxico vasco como "padre", "hijo", "hermano", "mozo", "chico", de escasa sofisticación.

107 Lillo 1992; Sanmartín 1988, 96-97. 
con el muy frecuente formante antroponímico teofórico cartaginés בעל /ba'1/ en transcripciones latinas -bal. Implícitamente los ejemplos sugieren explicar el vocalismo como resultante de la faringal (tal como en acadio bel), pero su interpretación de la sibilante final como un morfema íbero es un simple ad hoc. Por desgracia, al estar poco familiarizado con lo íbero no capta un ejemplo que podría reforzar su propuesta. Tal es el caso del antropónimo NEITINBELES. Por un lado, por las sospechas de que Neitin sea un teónimo (así "Neitin es señor" o similar), por otro, por permitir un completo paralelismo con nombres semíticos teofóricos con un sentido de "Baal ha dado", ${ }^{108}$ que hubiese encajado perfectamente con su línea argumental. Con todo, la comparación entre beleś y Baal, si bien no completamente descartable, es dudosa. Aparte de los problemas indicados, dada la alta frecuencia del formante, se esperaría una presencia clara en contextos votivos.

Otro término sospechoso es atun, cuya interpretación como teónimo es propuesta por Corzo et alii ${ }^{109}$ al tratar de BETATVN. Para ello presentan argumentos contextuales, en especial su relación con iunstir y una posible, pero en realidad cuestionable, ${ }^{110}$ con neitin; a lo que puede añadirse su aparente desinencia en -e en F.9.7. De hecho su argumentación puede reforzarse si tenemos en cuenta que el contexto entero es iunstir : atune : baŕbinkeai : uskeike, que es paralelo a la inscripción rupestre de Ger. ${ }^{111}$ Súmese también en F.6.1 : ekaŕ-iu : atun-iu : si tenemos en cuenta que uno de los dativos votivos rupestres sería ekaŕsor-e (o ekeŕsor-e). Como podemos ver, hay argumentos como mínimo para sospechar que tengamos un teónimo; pero, por desgracia, no está claro si es 'atun' o 'adun' (cf. NIC 18). En todo caso, si efectivamente es una divinidad, la comparación con Adon /Adonis es obvia. ${ }^{112}$

Otro posible caso es el tanito planteado en Rodríguez Ramos (NIC 136a) que hemos mencionado al tratar de artiunan. De acuerdo con las dos menciones en greco-púnico de Cirta, para Jongeling y $\operatorname{Kerr}^{113}$ la forma púnica original sería / $\theta \ni v \imath \theta /$ con evolución posterior a / $\theta \mathrm{v} v \mathrm{\theta} \theta$ / por armonía vocálica. Tendríamos pues una neutralización de vocal átona con timbre poco definido, por lo que la iberización en a no es obvia, pero entraría dentro de lo posible. La adaptación podría haberse visto favorecida por la analogía con los formantes TANNE- / taneś (NIC 136 y 137) y -ETON (NIC 60), el cual se documenta sólo en dos nombres de mujer, lo que encajaría con el femenino -t púnico.

Existe una cuarta posibilidad inédita. Al editar la inscripción rupestre de Osséja ile kutur Ferrer ${ }^{114}$ prefiere la interpretación como iŕe kutur, aunque no queda claro cómo encajaría esta estructura, típica de textos extensos, como términos únicos. En

108 En antroponimia hebrea todavía puede encontrarse, con la propia divinidad, en el nombre Netan-Yahu o incluso los equivalentes Natani-el y Jo-natan. Pero propiamente en fenicio tiene una presencia marginal (por ejemplo $n t n-b^{\prime} l$, Krahmalkov 2000, 338), pues predomina la raíz propia ytn (ytn-b'l o ytn-'l / Ia-ta-na-e-li, Krahmalkov 2000, 220).

109 Corzo et alii 2007, 255-256.

110 En el segmento que alegan, atuneitin (F.20.3), no está clara la segmentación inicial y, por ende, la presencia de atun.

111 Ferrer 2016.

112 Rodríguez Ramos 2017, 137. En greco-púnico el término aparece transcrito, aunque como epíteto, $\lambda$ - $\alpha \delta$ ovv (Jongeling - Kerr 2005, 79); en acadio tenemos $A$-du-ni-ba-a'-al (Friedrich - Röllig 1999, § 57) con la -i posesiva final propia del teónimo.

113 Jongeling - Kerr 2005, 80.

114 Ferrer 2017, 10-11. 
cambio, dentro de su interpretación votiva de la inscripción (apoyada por kutur) y la de buscar dativos teonímicos en -e, la otra intepretación es que il sea un teónimo. Bien, precisamente en púnico 'il / el' es tanto un término genérico para "divinidad" como el nombre específico del dios El, de forma que la interpretación "para el dios" o, mejor, "para El" es factible.

Finalmente pasamos a dos casos cuyo carácter de posible préstamo es planteado por tratarse de secuencias fonotácticas excepcionales en íbero: -lk- y -al\#. ${ }^{115}$

La primera es la comparación indicada en Rodríguez Ramos ${ }^{116}$ del frecuentísimo formante balke con el *malk semítico, "rey". Aunque el vocalismo coincidiría con el original semítico el problema es el innovado fenicio 'milk'. Pero además de la sugerencia de la propuesta original (participación en la colonización de otros semitas, como arameos cuya lengua era lingua franca en Oriente) hay alguna posibilidad más. En las transcripciones greco-latinas de términos fenicios las i pueden aparecer también como e y, de hecho, parece que en muchos casos el fonema /i/ tenía como alófono /e/, lo que facilitaría la interpretación; mientras que en la onomástica fenicia se usan formas del verbo reinar, donde se mantiene la vocal 'a'.117

Pero la conexión es más fácil si entendemos que su variante balkar se corresponde con el fenicio milk-qart, es decir, el nombre del dios Melqart, donde podría suponerse que la primera vocal se ha asimilado a la segunda por armonía vocálica. Esto podría haber influido en balke o éste sería un apócope de Melqart. Pero, como veremos, el caso siguiente nos sugerirá otra posibilidad.

Esta comparación se hace más probable desde el momento que coincide con ser balkar uno de los términos que Ferrer ${ }^{118}$ considera que por su repetición en inscripciones rupestres podría ser un nombre de divinidad precisamente de culto extendido ("supralocal"). Debe notarse que, aunque por desgracia no hay un contexto claro para la cerámica ática G.3.1 con la inscripción greco-ibérica balkar, interpretarlo como teónimo tiene la ventaja de resolver el problema de que en compuestos antroponímicos sólo aparece como segundo formante. De esta manera la comparación de balkar con Melqart resulta especialmente prometedora. ${ }^{119}$

Finalmente, tenemos el caso del misterioso -al que Ferrer considera que permite identificar nombres de dioses. De ser esto realmente así, existen dos interpretaciones

115 Sobre la rareza de -l final Quintanilla 1998, 251-252; sobre el grupo -lk- Rodríguez Ramos 2004, 247. En general se aprecian unas marcadas diferencias en el uso fonotáctico entre $\mathbf{l}$, ́́ y $\mathbf{r}$ con tendencia a distribuciones complementarias (Rodríguez Ramos 2004, 247-250 y 328-329) que sugieren fenómenos de alofonía, sean activos o fonologizados heredados de una fase anterior.

116 Rodríguez Ramos 2018, 209.

117 Ba-'a-al-ma-lu-ku (Assurb. II 84) = Ba 'l-malók, "Ba'l hat sich als König erwisen" (Friedrich - Röllig 1999, § $78 \mathrm{c})$.

118 Ferrer 2019, 48-49.

119 Este testimonio es especialmente importante dado que, por lo indicado, no encaja con el patrón esperable para un antropónimo (en otros casos puede plantearse un nombre teofórico y en las rupestres el contexto y la datación son siempre problemáticos). Por desgracia, su yacimiento, La Condomina (Benilloba), parece no haber sido todavía excavado, sino conocerse sólo por prospecciones. En todo caso es interesante indicar que se encuentra muy cerca de La Serreta de Alcoy y que tanto para éste como para el de La Illeta dels Banyets (donde además de diversos grafitos greco-ibéricos se documentan púnicos) hace años que se viene señalando la presencia de templos con influencias púnicas. Véase Llobregat 1994 para la propuesta en sí, aunque hay abundante bibliografía sobre esto y sobre la influencia púnica en la religión contestana. En el sentido de lo que examinamos es sugerente, pero obviamente nada probatorio por poder ser un antropónimo abreviado, comparar el texto único del grafito de La Illeta (G.9.4) bal con Baal. 
púnicas que podrían argüirse para explicar tanto el final, fonéticamente excepcional, como el uso para nominar divinidades.

La primera opción sería entender que es una importación del término "dios", que en fenicio aparece normalmente en plural con sentido singular como ilim, pero también en la forma de singular normal il / el, pero incluso con 'a' en el plural allonim. ${ }^{120}$ En tal caso las formas en -al se entenderían como compuestos del tipo "dios de X".

El problema es, de nuevo, un vocalismo para el que preferiríamos el mantenimiento de /i/ o al menos /e/ (en especial si recordamos que los finales en -l íberos son formas como sekel o tetel). Pero si tenemos en cuenta la sospechosa coincidencia de que son dos formas anómalas en íbero las que aparecen como al, quizás pueda plantearse el que la ' 1 ' púnica en posición implosiva tuviese un sonido distinto a la íbera (quizás más velar) que a oídos íberos abriese la vocal. ${ }^{121}$

Alternativamente existe otra posibilidad de préstamo, con buena correspondencia con teónimos púnicos, pero fonéticamente más complicada. Los finales en al serían finales Baal y los teónimos serían del tipo "señor de", pero donde habría que suponer que en una fase del préstamo habría caído la b inicial.

Ambas posibilidades son tentadoras en tanto que proporcionarían una interpretación semántica acorde y explicarían el final atípico, pero las dificultades fonéticas no son menores. Por otra parte, restaría por explicar la extraña (en términos del íbero conocido) forma composicional de casos como los supuestos urte-al y okV-al.

\section{Conclusiones}

La identificación de los nombres de dioses de los íberos es una investigación todavía en fase muy inicial. Es muy poco lo que se conoce a partir de las inscripciones latinas, por más que es probable que se produzca alguna novedad epigráfica, quién sabe si relevante; es decir, que dé información que conecte con las inscripciones íberas. Similarmente, el campo de comparación con lo aquitano, pese a ser muy recurrido, ha arrojado unos resultados muy magros, poniendo en duda el presupuesto de su estrecha relación.

Es probable que alguna de las marcas de propiedad íberas escondan, bajo la apariencia de un antropónimo, en realidad alguna divinidad. En inscripciones más complejas sobre objetos de un cierto valor o estelas pueden empezar a señalarse aparentes beneficiarios en "dativo" que, aunque como en etrusco podrían ser regalos a personas, verosímilmente presentan más de un nombre de divinidad. Pero uno de los principales problemas es la escasez de repeticiones entre estos términos sospechosos. En esto merece especial atención la aparición del segmento betan / bitan.

Un terreno que ha proporcionado interesantes resultados son las novedades epigráficas rupestres, estudiadas y revisadas por Ferrer, quien recientemente ha hecho

120 Krahmalkov 2000, 49, 'l y 52, 'lm. De hecho también menciona un uso en singular de la forma 'ln que propone vocalizar 'allōn (Krahmalkov 2000, 53).

121 La combinatoria de $\mathbf{l}$ íbera sí apunta a realizaciones singulares: es rarísima en posición final (los casos mencionados en -el), en posición implosiva sólo es normal ante s y t , e incluso en posición inicial parece evitarse la secuencia li- (quizás por una palatalización). 
un especial esfuerzo por detectar términos que puedan ser teónimos. Especialmente interesantes son sus observaciones sobre las coincidencias de finales en -al y la atención a los casos del monograma de ka(uŕ)ko(ŕ). Pero, aunque sus resultados arrojan diversas propuestas plausibles, éstas no están exentas de problemas, tanto por las dificultades intrínsecas del material, como por su empeño en identificar morfos que, cual partículas divinas, estén ahí para que identifiquemos teónimos sin reparar en si eso tiene sentido en una lengua real o cuál sería.

Por eso aquí se ha enfatizado el enfoque lingüístico real. Es mediante el conocimiento de las estructuras de la lengua, sintáctica y morfológica, sobre todo de las formas de indicar el "dativo", como mejor podemos entender las inscripciones y decidir entonces si una inscripción es religiosa y qué puede ser un nombre de divinidad.

También se ha incidido en otro aspecto que por paralelos epigráficos objetivos es esperable en las inscripciones íberas: la de importación de nombres de dioses extranjeros, de culturas "superiores". En especial en un terreno tradicionalmente negligido por la iberística, tan influido por la filología clásica que ve normal comparar las inscripciones íberas con inscripciones romanas de época imperial, pero para la que toda la cultura del periodo orientalizante parece no existir. Por eso aquí se ha prestado especial atención a lo púnico y a las tradiciones epigráficas relacionadas con lo fenicio. Si las propuestas aquí apuntadas resultan correctas, sólo el tiempo lo confirmará; pero no son en absoluto peores a las alternativas actuales. En especial, el intento de resolver las rarezas fonotácticas como préstamos (algo bien acreditado por la lingüística) percibiendo su parecido con lo púnico para -al, pero sobre todo la ecuación balkar / Melqart parece especialmente prometedora.

Por lo demás, puede que el lector espere aquí un resumen de los "mejores" teónimos. Mas no quisiera el autor de estas líneas nublar el criterio del lector destacando aquí las propuestas presentadas como algo seguro. Lo mejor que puede hacer una conclusión es recomendarle que lea los argumentos y extraiga sus propias conclusiones. Nuestros conocimientos sobre lo íbero están, podríamos decir, como en estado de flujo o casi cuántico: conviene más percibir probabilidades que aferrarnos por comodidad a supuestas certezas.

\section{Referencias bibliográficas}

Almagro Gorbea, M. (2002): "Una probable divinidad tartésica identificada: Niethos/Netos", Palaeohispanica 2, 37-70 (https://doi.org/10.36707/palaeohispanica.v0i2.347).

Artigues, P. L. - Codina, D. - Moncunill, N. - Velaza, J. (2007): “Un colgante ibérico hallado en Can Gambús (Sabadell)", Palaeohispanica 7, 239-250.

Beltrán Lloris, F. (2014): "De inscripciones vasculares pintadas y lugares de culto ibéricos: sobre el 'santuario urbano' de Liria”, [en] P. Bádenas de la Peña et alii (eds.), Homenaje a Ricardo Olmos. Per speculum in aenigmate. Miradas sobre la Antigüedad, Madrid, 325329.

Beltrán Lloris, M. (1974): "La palabra iunstir, el plomo de Alcoy y algunos problemas del vascoiberismo", [en], J. Ma Blázquez, (ed.), Homenaje a D. Pío Beltrán (=Anejos de Archivo Español de Arqueología VII), Zaragoza, 21-72.

Campbell, L. (1998): Historical linguistics. An Introduction, Edinburgh. 
Correa Rodríguez, J. A.

(1992): "Representación gráfica de la oposición de sonoridad en las oclusivas ibéricas (semisilabario levantino)", Annali del Dipartimento di Studi del Mondo Classico e del Mediterranio Antico. Sezione linguistica 14, 253-292.

(1994): "La lengua ibérica", Revista Española de Lingüística 24/2, 263-287.

Corzo Pérez, S. - Pastor Muñoz, M. - Stylow, A. U. - Untermann, J. (2007): “Betatun, la primera divinidad ibérica identificada", Palaeohispanica 7, 251-262.

Díaz Ariño, B. - Mínguez, J. A. (2009): “Un nuevo grafito ibérico procedente del yacimiento de La Cabañeta (El Burgo de Ebro, Zaragoza)", Palaeohispanica 9, 435-450.

Eiroa, J. J. (1986): "El kalathos de Elche de la Sierra (Albacete)", Anales de Prehistoria y Arqueología Universidad de Murcia 2, 73-86.

Ferrer i Jané, J.

(2005): "Novetats sobre el sistema dual de diferenciació gràfica de les oclusives sordes i sonores", Palaeohispanica 5, 957-982.

(2015): "Le nouveau corpus d'inscriptions ibériques rupestres de la Cerdagne: deuxième parution", Sources 3, 7-22.

(2016): "Une inscription rupestre ibère inédite de Ger (Cerdagne) avec la formule «neitin iunstir»", Sources 4, 13-28.

(2017): "Nouveau corpus d'inscriptions ibériques rupestres de la Cerdagne (3): cinq inscriptions inédites", Sources 5, 7-21.

(2018a): "A la recerca dels teònims iberics: a propòsit d'una nova lectura d'una inscripció ibèrica rupestre d'Oceja (Cerdanya)", [en] Vallejo - Igartua - García (eds.), 2018, 101 126.

(2018b): "Revisión de las inscripciones ibéricas rupestres del Abrigo del Tarragón (Losa del Obispo): primeros resultados", Estudios de Lenguas y Epigrafía Antiguas 17, 221261.

(2019): “Construint el panteó ibèric amb l'ajut de les inscripcions ibèriques rupestres", Ker 13, $42-57$.

Ferrer, J. - Velaza, J. - Olesti, O. (2018): "Nuevas inscripciones rupestres latinas de Oceja y los IIIIviri ibéricos de Iulia Lybica", Dialogues d'histoire ancienne 44/1, 169-220 (https://doi.org/10.13140/RG.2.2.10953.85609).

Fletcher Valls, D. (1985): Textos ibéricos del Museo de Prehistoria de Valencia (=Servicio de Investigaciones Prehistóricas. Trabajos Varios 81), Valencia.

Friedrich, J. - Röllig, W. (1999): Phönizisch-punische Grammatik. 3 Auflage, neu bearbeitet von Maria Giulia Amadasi Guzzo unter mitarbeit von Werner R. Mayer, Roma.

Gesenius, W. (2013): Hebräisches und Aramäisches Handwörterbuch über das Alte Testament. 18 Auflage, Berlin-Heidelberg (ed. H. Donner).

González Román, C. (2002): "La colonia Iulia Gemella Acci y la evolución de la Bastetania", [en] C. González Román, Ciudad y privilegio en Andalucía en época romana, Granada, 135-166.

De Hoz Bravo, J.

(1979): "Escritura e influencia clásica en los pueblos prerromanos de la Península", Archivo Español de Arqueología 52, 227-250.

(1985): "El nuevo plomo inscrito de Castell y el problema de las oposiciones de sonoridad en Ibérico", [en] J. L. Melena (ed.), Symbolae Ludovico Mitxelena septuagenario oblatae (=Anejos de Veleia. Series Maior 1), Vitoria-Gasteiz, vol. I, 443-453.

(2011): Historia lingüistica de la Península Ibérica en la Antigüedad: Vol. II. El mundo ibérico prerromano y la indoeuropeización (=Manuales y Anejos de Emerita 51), Madrid. 
Hübner, E. (1893): Monumenta Linguae Ibericae, Berlin.

Jamme, A. (1966): Sabaean and Hasaean inscriptions from Saudi Arabia (=Studi semitici 23), Roma.

Jongeling, K. - Kerr, M. R. (2005): Late Punic Epigraphy, Tübingen (https://doi. org/10.1628/978-3-16-151140-0).

King, G. M. H. (1990): Early North Arabian Hismaic, PhD. diss., University of London, School of Oriental and African Studies.

Krahmalkov, Ch. R. (2000): Phoenician-Punic Dictionary (=Studia Phoenica XV), Leuven (https://doi.org/10.1163/9789004294202).

Lillo, A. (1992): “Los antropónimos íberos en (-)beleś(-)”, Aula Orientalis 10, 258-260.

Llobregat, E. (1994): "Tradición religiosa fenicio-púnica en Contestania", [en] M. Molina Martos - J.-L. Cunchillos - A. González Blanco (coords.), El mundo púnico: Historia, sociedad y cultura (=Biblioteca Básica Murciana. Extra 4), Murcia, 169-176.

Maluquer de Motes i Nicolau, J. (1968): Epigrafía prelatina de la Península Ibérica (=Publicaciones eventuales 12), Barcelona.

Mariner Bigorra, S. (1972): “Adaptaciones latinas de términos hispánicos”, [en] Homenaje a Antonio Tovar ofrecido por sus discípulos, colegas y amigos, Madrid, 283-299.

Matasović, R. (2009): Etymological Dictionary of Proto-Celtic (=Leiden Indo-European Etymological Dictionary Series 9), Leiden-Boston.

Moncunill, N. - Ferrer i Jane, J. - Gorrochategui, J. (2016): "Nueva lectura de la inscripción ibérica sobre piedra conservada en el Museo de Cruzy (Hérault)", Veleia 33, 260-274 (https://doi.org/10.1387/veleia.16981).

Nebes, N. (2010): "Eine apotropäische Segensformel in den äthio-sabäischen Königsinschriften”, Aethiopica 13, 182-188 (https://doi.org/10.15460/aethiopica.13.1.45).

Orduña Aznar, E.

(2005): Segmentación de textos ibéricos y distribución de los segmentos, Tesis doctoral, UNED, Madrid.

(2018): "Cuestiones de morfología nominal relacionadas con la epigrafía votiva ibérica y aquitana", [en] Vallejo - Igartua - García (eds.), 2018, 413-428.

(2019): "The Vasco-Iberian theory", [en] A. G. Sinner - J. Velaza (eds.), Palaeohispanic Languages and Epigraphies, Oxford, 219-239 (https://dx.doi.org/10.1093/ oso/9780198790822.003.0009).

Pallotino, M. (19847): Etruscologia, Milano.

Pokorny, J. (1959-1969): Indogermanisches etymologisches Wörterbuch, Bern-München $(=\mathrm{IEW})$.

Quintanilla, A.

(1993): "Sobre la notación en la escritura ibérica del modo de articulación de las consonantes oclusivas", [en] I. J. Adiego - J. Siles - J. Velaza(eds.), Studia Palceohispanica et Indogermanica J. Untermann ab amicis hispanicis oblata (=Aurea saecula 10), Barcelona, 239-250.

(1998): Estudios de fonología íbera (=Anejos de Veleia. Series Minor 11), VitoriaGasteiz.

Ramos, R. (2019): Los iberos. Imágenes y mitos de Iberia, Córdoba.

Rodríguez Ramos, J.

(1994): “Liria XIIC (sic): ¿un kálathos ibérico dedicado a Proserpina?”, Faventia 16/2, $65-81$.

(1995a): Breve manual de epigrafía ibérica, Barcelona.

(1995b): "Nota a la inscripción ibérica Tarragona C. 18.8”, Pyrenae 26, 123-125. 
(1997): "Primeras observaciones para una datación paleográfica de la escritura ibérica", Archivo Español de Arqueología 70, 13-30 (https://doi.org/10.3989/aespa.1997.v70.255). (2000): "La lengua íbera: en busca del paradigma perdido", Revista Internacional d'Humanitats 3, 9-22.

(2001): "Sobre los signos de lectura problemática en la escritura ibérica levantina y una inscripción revisada", Archivo Español de Arqueología 74, 281-290 (https://doi. org/10.3989/aespa.2001.v74.156).

(2002a): "La hipótesis del vascoiberismo desde el punto de vista de la epigrafía íbera", Fontes Linguae Vasconum 90, 197-217.

(2002b): “Acerca de los afijos adnominales de la lengua íbera", Faventia 24/1, 115-134. (2004): Análisis de Epigrafía Íbera (=Anejos de Veleia. Series Minor 22), Vitoria-Gasteiz. (2005a): "Introducció a l'estudi de les inscripcions ibèriques", Revista de la Fundació Privada Catalana per a l'Arqueologia Ibèrica 1, 13-144

(2005b): "La problemática del sufijo «primario» o «temático»-k- en la lengua íbera y del vocabulario de las inscripciones religiosas íberas", Faventia 27/1, 23-38.

(2005-2006): “Observaciones sobre algunas inscripciones ibéricas", Kalathos 24-25, 461-473.

(2008): "Comentaris epigrafics a les inscripcions d'Olèrdola" [en] N. Molist - D. Asensio (eds.), La Intervencio al sector 01 del conjunt historic d'Olèrdola: de la prehistoria a l'etapa romana (campanyes 1995-2006), (=Monografies d'Olèrdola 2), Barcelona, 581588.

(2014): "Nuevo Índice Crítico de formantes de compuestos de tipo onomástico íberos", Arqueoweb 15/1, 81-238 (=NIC).

(2016): "Sobre las marcas de agente en íbero", Philologia Hispalensis 30/1, 233-261 (http://dx.doi.org/10.12795/PH.2016.i30.12).

(2017): "La cuestión del dativo en la lengua íbera", Philologia Hispalensis 31/1, 119-150 (https://doi.org/10.12795/ph.2017.i31.06).

(2018): "Estudio de fenómenos consonánticos de la lengua íbera", Veleia 35, 189-211 (https://doi.org/10.1387/veleia.17573).

Sanmartín Ascaso, J. (1988): "Silabografías y segmentabilidad fonológica: travestidos gráficos en los silabarios antiguos", Aula Orientalis 6/1, 83-98.

Silgo Gauche, L. (1994): Léxico ibérico (=Estudios de Lenguas y Epigrafías Antiguas 1), Valencia.

Simón Cornago, I.

(2009a): "C.18.8. una inscripción ibérica suspecta", Arse 43, 51-61.

(2009b): "Una inscripción ibérica sobre un árula de Tarragona (C.18.7)", Palaeohispanica 9, 517-530.

Untermann, J.

(1984): "Inscripciones sepulcrales ibéricas", Cuadernos de Prehistoria y Arqueología de Castellón 10, 111-119.

(1985): "Nuevos textos ibéricos sobre plomo", Acta Numismàtica 15, 33-46

Vallejo, J. M M $^{\mathrm{a}}$ Igartua, I. - García Castillero, C. (eds.), (2018): Studia philologica et diachronica in honorem Joaquín Gorrochategui (=Anejos de Veleia. Series Minor 35), Vitoria-Gasteiz.

Velaza Frías, J.

(2002): "Chronica Epigraphica Iberica IV (2001)", Palaeohispanica 2, 411-414.

(2015): "Salaeco: un teónimo ibérico", Zeitschrift für Papyrologie und Epigraphik 194, 290-291. 
(2016): "Recensión a J. Untermann, Iberische Bleiinschirften in Südfrankreich und im Empordà, Madrider Forschungen Band 20, Berlin/Boston, De Gruyter, 2014", Ancient West \& East 15, 482-484.

Vidal, J. C. (2016): "Interpretació ibèrica de dos teònims preromans del nord-est peninsular", Revista d'Arqueologia de Ponent 26, $195-204$ (https://doi.org/10.21001/rap.2016.26.10). Vizcaíno Esteban, A. (2015): "Productores, usuarios y usos de los vasos singulares del Tossal de Sant Miquel de Llíria (Valencia)", Verdolay 14, 67-88. 